\title{
Alternative Measures of the Federal Reserve Banks' Cost of Equity Capital
}

\author{
Michelle L. Barnes and Jose A. Lopez
}

\begin{abstract}
:
The Monetary Control Act of 1980 requires the Federal Reserve System to provide payment services to depository institutions through the twelve Federal Reserve Banks at prices that fully reflect the costs a private-sector provider would incur, including a cost of equity capital (COE). Although Fama and French (1997) conclude that COE estimates are "woefully" and "unavoidably" imprecise, the Reserve Banks require such an estimate every year. We examine several COE estimates based on the Capital Asset Pricing Model (CAPM) and compare them using econometric and materiality criteria. Our results suggest that the benchmark CAPM applied to a large peer group of competing firms provides a COE estimate that is not clearly improved upon by using a narrow peer group, introducing additional factors into the model, or taking account of additional firm-level data, such as leverage and line-of-business concentration. Thus, a standard implementation of the benchmark CAPM provides a reasonable COE estimate, which is needed to impute costs and set prices for the Reserve Banks' payments business.
\end{abstract}

JEL Classifications: G11, G28

Keywords: cost of equity; return on equity; CAPM; payments system

Michelle L. Barnes and Jose A. Lopez are Senior Economists at the Federal Reserve Bank of Boston and the Federal Reserve Bank of San Francisco, respectively. Their respective email addresses are michelle.barnes@bos.frb.org and jose.a.lopez@sf.frb.org.

This research was initiated by the 2004 PSAF Review conducted by the Financial Services Product Committee of the Federal Reserve System. We thank Tony Saunders (the editor) and an anonymous referee for their comments on this paper. We thank Tara Rice for her assistance with payments revenue issues and for sharing her programs and data with us. We thank Franklin Allen, Greg Evans, Ed Green, Anil Kashyap, Richard W. Kopcke, John Krainer, Andy Kuritzkes, Andy Messier, Loretta Mester, Paul Rimmereid, Richard Rosen, Joanna Stavins, Herb Taylor, Anjan Thakor, Dave Tremblay, and participants at the 2004 Federal Reserve System Conference on Financial Structure and Regulation for their comments and suggestions. We thank Paul Schwabe, Felix Momsen, and Nicolas Duquette for their research assistance.

This paper, which may be revised, is available on the web site of the Federal Reserve Bank of Boston at http://www.bos.frb.org/economic/ppdp/index.htm.

The views expressed in this paper are solely those of the authors and do not reflect official positions of the Federal Reserve Bank of Boston or the Federal Reserve System.

This version: September 23, 2005 


\section{Introduction}

The Monetary Control Act (MCA) of 1980 requires the Federal Reserve System to provide payment services, such as check clearing and electronic funds transfers, to depository institutions through the twelve Federal Reserve Banks at prices that fully reflect the costs a private-sector provider would incur in providing those services. ${ }^{1}$ The MCA requires the imputation of various financial costs, such as taxes and funding costs, that the Reserve Banks would incur if their payments services business were a commercial enterprise. To comply with the provisions of the MCA, the Federal Reserve System has established a methodology, known as the Private Sector Adjustment Factor (PSAF), for imputing these costs.

A key component of the PSAF calculation is the weighted average cost of capital for the Reserve Banks' payments business. In this paper, we focus on the cost of equity capital (COE), which is the imputed return on the business's determined level of equity capital. ${ }^{2}$ The COE calculation within the PSAF methodology has been revised over the years, and the current estimation method is described in Green et al. (2003). ${ }^{3}$ Basically, this COE calculation involves selecting a peer group of comparable firms and estimating their cost of equity capital, using publicly available information and established quantitative methods, such as the CAPM.

However, Fama and French (1997) conclude that COE estimates based on the CAPM approach are "woefully" and "unavoidably" imprecise, with typical standard errors of more than an annualized 3 percent at the industry level and greater at the firm level. ${ }^{4}$ In fact, Fama and French (2004) conclude that the weaknesses of the CAPM approach imply that "most applications of the model are invalid." Regardless of this strong caveat, the operational needs of

\footnotetext{
1 For a general description of the Federal Reserve System's participation in the payments system, see Board of Governors of the Federal Reserve System (1990) and Committee on the Federal Reserve in the Payments Mechanism (1998). See Gilbert et al. (2004) for a description and efficiency analysis of the Federal Reserve Banks' payments services business.

2 For the PSAF calculations, the Federal Reserve System has chosen bank holding companies as the set of comparable firms. Hence, the level of imputed equity capital is set at 5 percent of total assets and at 10 percent of total riskweighted assets to comply with FDIC guidelines for a well-capitalized banking institution; see Part 325 - Capital Maintenance of the FDIC Rules and Regulations for further details.

${ }^{3}$ In 2004, the Federal Reserve System formed a work group to review this calculation; see Board of Governors of the Federal Reserve System (2005) for the methodology to be used starting in 2006.

4 Fama and French (1997) determined that these large standard errors are driven primarily by uncertainty about the expected risk factor premiums as well as by imprecise estimates of the model parameters.
} 
the Federal Reserve Banks, as well as those of many private sector firms, require COE estimates for a variety of corporate purposes. Although a battery of estimation methods is used in practice, the CAPM approach appears to be the most prevalent, as shown in the survey results in Bruner et al. (1998) as well as those of Graham and Harvey (2001).

While there appears to be general agreement regarding the use of the CAPM approach for COE estimates, despite its known flaws, implementation practices seem to vary considerably. Within the CAPM approach, several important empirical choices must be made, such as:

- Which publicly traded firms should be included in the peer group?

- Should additional factors be added to the benchmark CAPM?

- What econometric methods should be used for estimating the model?

- Is it helpful to incorporate firm-specific factors, such as leverage and line-ofbusiness concentration, into the COE estimates?

In this paper, we examined these questions directly for the Reserve Banks' payments services business, using two general methodologies.

First, we used common model selection criteria and hypothesis testing methods to examine whether it is appropriate to introduce additional factors to the benchmark CAPM. These in-sample modeling techniques, however, cannot address non-nested estimation issues, such as peer group selection. Hence, we used a second methodology to examine whether COE estimates generated by alternative calculation methods differ significantly from COE estimates based on the benchmark approach. For our analysis, we generated almost 200 alternative COE estimates for the Reserve Banks' payments business, using various modeling decisions. By comparing these alternative measures directly, we can assess the statistical importance of these modeling choices on the COE estimates for our specific application and hopefully provide insight regarding COE estimation more generally. Note, however, that although differences between COE estimation methods may not be statistically significant, they may still lead to economically relevant differences in the COE estimates and, hence, in the service costs and prices generated by the Federal Reserve's PSAF methodology. 
As suggested by the questions above, the modeling decisions we examined were the peer group choice, the CAPM specification, the estimation technique used, and the firm-specific adjustments used in generating the COE estimates. Consistent with the 2005 PSAF methodology, the alternative peer groups we examined all consisted of publicly traded bank holding companies (BHCs). This choice is limiting in several ways, especially since BHCs do not engage exclusively in the payments services businesses of interest to the Reserve Banks. From the perspective of the Federal Reserve System's payments business, arguably banker's banks, with wholesale payments business rather than retail, are a more appropriate comparison group. However, given the difficulties of easily identifying payments services firms that are publicly traded over time, BHCs are a reasonable proxy and have been used in the PSAF calculations historically. Our largest peer group consisted of the 47 publicly traded BHCs with five years of trading data in the list of top fifty BHCs sorted by deposits as of year-end 2003; see Table 1 for the complete list. Using this peer group as our benchmark, we found that narrowing the peer group using various economic criteria did not generate COE estimates that were statistically different, on average, from the benchmark.

For the CAPM specification, we examined whether it was appropriate to introduce additional factors relevant to BHCs and their payments services businesses into the single-factor CAPM. Specifically, we included an interest-rate factor and a proxy for BHCs' payments revenues. Based on in-sample statistical criteria, we found that including these variables did not improve the benchmark model's in-sample fit in a statistically meaningful way. Hence, the parsimonious benchmark specification was the most appropriate for our exercise.

This specification result was based on individual regressions for the BHCs in the candidate peer groups. We also used a panel-regression framework to take advantage of any additional information that might be present, as per Barnes and Hughes (2001). The panelregression results for the largest peer group suggested that these additional factors were statistically significant within the CAPM. However, further in-sample evidence showed that the differences between the fitted values from multi-factor models estimated using panel-regression methods and the benchmark single-factor model estimated for individual peer group BHCs are 
not material. Hence, we concluded that panel estimation methods did not provide material improvements to the COE estimates and were not appropriate for our exercise.

Finally, we examined different firm-level adjustments to the COE estimates that have been discussed in the literature with respect to the single-factor CAPM. Specifically, we incorporated firm leverage and line-of-business concentrations into the COE estimates indirectly by adjusting the firm equity betas or directly by adjusting the COE estimates themselves. Thus, we examined four adjustment types: no adjustment, a leverage-only adjustment, a line-of-business adjustment, and an adjustment for both factors. Looking across candidate peer groups and CAPM specifications, we cannot reject the null hypothesis that the adjusted COE estimates are equal to the unadjusted estimates, on average. We concluded that adjusting our COE estimates to address these concerns raised in the literature was not statistically significant, and hence, not appropriate for our exercise.

In sum, our analysis suggests that the COE estimates generated by the single-factor CAPM, estimated using individual BHC regressions for a relatively large BHC peer group, are reasonable for our purposes. ${ }^{5}$ While there are various important empirical decisions to be made ex ante, our results indicate that these decisions do not generate materially different COE estimates than simpler methods. Since an important goal of the PSAF methodology used by the Reserve Banks for estimating their imputed cost of equity capital is public replicability, using these simpler methods would seem to be preferred. However, the caveats regarding the theoretical validity and empirical accuracy of the COE estimates generated by the CAPM must always be kept in mind.

The paper is structured as follows. Section 2 provides background on the needed COE estimates and the empirical issues we address here. Section 3 discusses the various peer groups we considered. Section 4 presents the various specifications of the CAPM we investigated and our empirical results. Section 5 presents our analysis of the firm-specific adjustments that we considered, and Section 6 concludes.

\footnotetext{
${ }^{5}$ As noted in Board of Governors of the Federal Reserve System (2005), the Federal Reserve System has chosen to set their beta parameter at a constant value of 1, starting in 2006.
} 


\section{Historical Context and the Key Empirical Issues Examined}

The Federal Reserve System provides payments services, such as check clearing and funds transfer capabilities, to depository institutions in the United States through the twelve Federal Reserve Banks. The Monetary Control Act (MCA) of 1980 requires that these services be provided at prices that fully reflect the costs a private-sector provider would face. Correspondingly, the MCA requires the imputation of various financial costs, such as taxes, interest payments on debt financing, and the cost of equity capital (COE). To comply with these provisions of the MCA, the Federal Reserve System established a methodology, commonly referred to as the Private Sector Adjustment Factor (PSAF), for imputing these costs as well as a variety of others. In this paper, our emphasis is on the COE estimate, which is interpreted to be the return that must be provided to equity investors in order to entice them to purchase common shares of this payments service business. ${ }^{6}$

The overall cost of the Reserve Banks' payments business is the sum of actual operating expenses, imputed costs such as various taxes, and the required COE expenses; see Table 2 for a historical accounting of these costs for the period from 1990 through 2003. The MCA requires the Federal Reserve System to recover all costs over the long run, which has been interpreted to be a rolling ten-year window. The prices charged for the Reserve Banks' different payments services, and hence their revenues, are determined using a variety of pricing mechanisms that are inherently nonlinear functions of the annual COE estimates and the overall cost recovery objective. For the ten-year period from 1994 to 2003, the Federal Reserve System recovered about 98 percent of total costs, but the recent trend has been toward diminishing cost recovery.

Shortly after the MCA was passed, the Federal Reserve System formulated the PSAF methodology based on the assumption that the nearest competitors to the payments services business were bank holding companies (BHCs). ${ }^{7}$ Hence, the COE estimate incorporated into the

\footnotetext{
${ }^{6}$ Thomson (2001) argues that different COE measures could be used for Reserve Bank payments services that are paper-based and those that are electronic. However, only an aggregate COE estimate is currently calculated and considered here.

7 A variety of different sets of competitors were considered before the so-called "bank holding company model" was decided upon; see U.S. Congress (1983) for further information. Subsequent reviews of the PSAF methodologies have revisited the question of appropriate competitors, but they have retained BHCs as the nearest competitors that can be readily and consistently identified over time, using publicly available data.
} 
PSAF calculations has been based on an average cost of capital for large BHCs. The PSAF methodology and its COE calculation have been revised several times since inception. ${ }^{8}$ In all such reviews, the Federal Reserve System has revised the PSAF methodology with the goal of adopting an imputed COE estimate that would:

1) provide a conceptually sound basis for economically efficient pricing;

2) be consistent with actual Reserve Banks' financial information;

3) be consistent with economy-wide practice, and particularly with private-sector practice, in accounting and applied financial economics; and

4) be intelligible and justifiable to the public, and replicable from publicly available information.

This last goal is based on the Reserve Banks' desire to comply strictly with the conditions within the MCA.

As described in Green et al. (2003), COE estimates from 2002 through 2005 were the average of three different estimation methods: the comparable accounting earnings (CAE) method, the discounted cash flow (DCF) method, and the capital asset pricing model (CAPM) method. The CAE method is based on accounting values and calculates COE as the ratio of net income to the book value of equity. This method has been used since the PSAF's inception. A key shortcoming of the CAE method, however, is its reliance on historical balance-sheet data, which are backward-looking in nature.

The DCF method is based on the standard assumption that a firm's stock price is the discounted present value of all expected future dividends. Given the price of the firm's equity and its expected future dividends, one can use this assumption to solve for the appropriate discount factor, which is the COE estimate. The DCF method is still used in some rate setting exercises for public utilities; see Vander Weide (2004) for a recent example. However, its reliance on analyst projections of earnings and dividends is an important shortcoming.

The third method currently used is the standard CAPM approach, in which the COE estimate is the sum of the relevant risk-free rate and a firm-specific equity premium. The firm's

\footnotetext{
8 See Eisenmenger et al. (1980); Division of Federal Reserve Bank Operations, Board of Governors of the Federal Reserve System (1983); Quick and Salop (1985); Wall (1988); and Green et al. (2003).
} 
risk premium is a fixed proportion of the overall market's risk premium. The proportionality factor is commonly known as the firm's equity beta. This parameter is most commonly estimated using the standard, one-factor CAPM, although multi-factor models are also used regularly.

In 2004, the Federal Reserve System chose to review certain aspects of the PSAF methodology and the COE estimation procedure in particular; that review was the starting point for this study. In consultation with an advisory group of academic and private-sector consultants, the decision was made to go out for public comment on the use of just the CAPM method, despite its well-known theoretical and empirical flaws. This decision was supported by survey evidence, as cited by Bruner et al. (1998) as well as Graham and Harvey (2001), that the majority of market participants consider the CAPM method most appropriate. Furthermore, most textbook treatments of equity cost of capital calculations are based on the CAPM; see Damodaran (2001) for an example.

Yet, even within the CAPM method, there are important empirical issues to be considered. In this paper, we focus on four key empirical choices. The first choice is the appropriate peer group to which the Reserve Banks' payments services business should be compared. Since the initial development and implementation of the PSAF methodology in the early 1980s, the Federal Reserve System has been challenged to find an appropriate peer group. Ideally, the peer group would be engaged in the same activities as the Reserve Banks' payments business, but several studies over the years have found that there are no private sector firms that provide the same set of services. Consequently, this COE estimate can only be made with respect to firms providing similar services as part of their overall business. To date, the PSAF methodology has used a peer group consisting of large, U.S. publicly traded BHCs. In this paper, we experimented with differing criteria for narrowing the BHC peer group to determine the impact this choice has on the COE estimates.

The second key empirical choice we examined was whether additional factors, aside from the overall equity market return, should be included in the CAPM calculation; see Fama and French (1997) as well as Bower et al. (1984). With respect to BHCs, many empirical studies have concluded that an interest rate factor is appropriate since BHCs typically borrow funds 
with short-term maturities and lend funds with longer maturities. In addition, although payments revenues are difficult to calculate for individual BHCs, we included a proxy based on the measures proposed by Rice and Stanton (2003) in our CAPM specifications.

The third key empirical choice was the CAPM estimation method. For this study, we considered individual BHC regressions and a panel regression framework. ${ }^{9}$ For the individual BHC regressions, each peer group BHC's parameters were estimated separately, without reference to the other BHCs. The regression results were then aggregated to form the COE estimates for the Reserve Banks' payments business. As discussed by Barnes and Hughes (2001), panel-data estimation would explicitly take account of any useful information available in the cross-sectional stock return data. This method generates common parameter estimates for all peer-group BHCs and simplifies the generation of the desired COE estimates.

The fourth empirical choice we considered was whether to modify the COE estimates using firm-level adjustments, as discussed in the CAPM literature. Specifically, we incorporated firm leverage and line-of-business concentrations into the COE estimates indirectly, by adjusting the firm equity betas or directly by adjusting the COE estimates themselves. We examined four adjustment types: no adjustment, a leverage-only adjustment, a line-of-business adjustment, and an adjustment for both factors. While these adjustments to the COE estimates are conceptually appealing, their practical impact is not immediately clear; that is, do these adjustments lead to meaningful changes in the Reserve Banks' COE estimate? In this paper, we compare these alternative measures directly.

\footnotetext{
${ }^{9}$ Alternatively, we could create a portfolio of peer-group returns and regress this on the excess market return (market risk premium) to obtain a single beta for the entire peer group. This approach was used in Green et al. (2003). We did not pursue the portfolio approach here, since we have been working with BHC-specific factors, such as payments revenue share, that preclude this approach.
} 


\section{Defining the Peer Group for the Reserve Banks' Payments Business}

In textbook applications, the cost of equity capital for a specific project or division within a multi-line business firm should be determined using the so-called "pure play" approach. Within this approach, publicly traded firms exclusively engaged in the same line of business as the division in question are identified, and their COE estimates, properly weighted, generate the division's COE estimates..$^{10}$ Although simple in theory, the "pure play" approach is difficult to implement, since identifying firms that match a specific business line is typically not possible or is complicated by the lack of corresponding mono-line firms.

With specific reference to the Reserve Banks' payments services business, these difficulties are squarely in place. Up through 2005, the Federal Reserve System's efforts to impute a COE measure for its payments business have focused on two peer groups. The first group is publicly traded firms that specialize in the processing of financial transactions, whether physical or electronic, for financial institutions. ${ }^{11}$ While reasonable in several respects, this peer group has not historically been used in the PSAF calculations for several reasons. For example, like BHCs, some of these firms also engage in non-payments businesses, such as creating and managing customer affinity programs for merchants. In addition, creating objective criteria for identifying such firms over time, based only on publicly available data, is challenging. Finally, many of these firms are partly or majority owned by BHCs.

Hence, the second peer group, based exclusively on BHCs, has historically been chosen as the appropriate one. The primary reason for this choice is that BHC payment services, particularly their correspondent banking services, are most similar to the Reserve Banks' payment services. However, this choice is limiting in several ways. BHCs obviously provide a much wider array of services than just wholesale payments processing and correspondent banking services. Moreover, the array of BHC services may continue to broaden as they evolve in today's less-regulated financial environment. Nevertheless, given the difficulties of easily identifying payments services firms that are publicly traded, BHCs are a reasonable proxy and

\footnotetext{
${ }^{10}$ Note that this approach assumes that the capital structures of these peer-group firms are the same as that of the division.

${ }^{11}$ Current examples of such firms are Fiserv (ticker FISV), the Bisys Group (BSG), and Total System Services (TSS).
} 
have been used in the PSAF calculations historically; see U.S. Congress (1983; page 1011).

BHCs are readily identified here, based on their government charters and mandatory data filings with government supervisors. ${ }^{12}$ For this study, we set the largest peer group as BHCs that are ranked in the top 50 ("top 50") by deposits at year-end 2003 and that have been publicly traded for five years. The deposit ranking was chosen for our calculation, based on the reasoning that total bank deposits can be viewed as a reasonable proxy for BHC wholesale payment services. As of year-end 2003, 47 of the top 50 BHCs ranked by deposits met our criteria; see Table $2 .{ }^{13}$ Note that we adjust the BHC monthly stock returns and other balance sheet data for mergers over our five-year estimation period.

While using this larger peer group for generating the desired COE estimates is not unreasonable, there are also good reasons to narrow the size of the peer group, ranging from closer adherence to industry practice for COE calculations to applying further criteria relevant to the Reserve Banks' payments business. Three alternative peer groups are examined here. The first alternative is the 24 publicly traded BHCs that constitute the top 25 BHCs by deposits at year-end 2003. This choice was made simply to reduce the size of the peer group.

The second alternative peer group is based on selecting BHCs that are more closely related to the Reserve Banks' payments business with respect to revenues, capital structure, and imputed credit rating. This multi-stage application of criteria starts with the "top 50" peer group and removes those that are not also on the list of top 50 BHCs ranked by due-to balances, which are defined as deposits from other depository institutions and are considered to be a proxy for correspondent banking activities. ${ }^{14}$ From that sample, we selected BHCs with Tier 1 capital ratios within 20 percent of 10.4 percent, which is the 2003 imputed value for the Reserve

\footnotetext{
12 We identified BHCs using the BHCK9802 variable reported in the quarterly Y-9C supervisory reports. This variable identifies whether a reporting entity is a subsidiary BHC and, if so, whether its BHC parent files a Y-9C report. We are interested only in top-tier BHCs since they are the corporate entities that typically issue public equity and hence provide detailed financial information to the public. We identify top-tier BHCs by selecting BHCs that report BHCK9802 values of " 1 " or " 3 ".

${ }^{13}$ We make exceptions to the filter regarding trading for five years in order to capture three large BHCs. Specifically, we include HSBC North America, ABN Amro, and New York Community Bancorp, even though they started trading in July 1999, August 1999, and November 2000, respectively.

14 "Due-to balances" are defined as the sum of total transaction and nontransaction deposits by domestic and foreign depository institutions at all of a BHC's subsidiary banks. The bank-level Call Report variables used, as of year-end 2003, were RCONB551, RCONB552, RCON2213, and RCON2236.
} 
Banks. ${ }^{15}$ The sample is further reduced by dropping BHCs without an investment-grade rating (that is, rated below BBB). This "narrower" peer group consists of 20 BHCs, as listed in Table 1. The last peer group we consider consists of four global processing banks that specialize in payments activities, as identified by Rice and Stanton (2003), even though their exact set of activities do not map perfectly to those of the Reserve Banks. The four BHCs in this peer group are the Bank of New York, Mellon Financial, Northern Trust, and State Street.

Do these refinements of the BHC peer group have a material impact on the Reserve Banks' COE estimate? While the refinements have differing degrees of economic reasoning behind them, their actual usefulness can only be determined empirically. Given the desire within the PSAF methodology for consistency, simplicity, and public replicability, for the purposes of this paper's analysis the original "top 50" peer group was chosen as the benchmark to be favored if the changes to the COE estimates induced by these alternative peer groups are economically or statistically small.

\section{Nested CAPM Specification Issues and Empirical Results}

Although questioned extensively in the academic literature, the use of the CAPM approach for COE estimation is well established in practice. The benchmark single-factor CAPM for equity returns is typically specified as

$$
\mathrm{R}_{\mathrm{it}}-\mathrm{R}_{\mathrm{ft}}=\alpha_{\mathrm{i}}+\beta_{\mathrm{Ei}}\left(\mathrm{R}_{\mathrm{mt}}-\mathrm{R}_{\mathrm{ft}}\right)+\varepsilon_{\mathrm{it}},
$$

where $R_{\mathrm{it}}$ is a BHC merger-adjusted monthly stock return; $\mathrm{R}_{\mathrm{ft}}$ is the risk-free, one-month Treasury bill rate; $\alpha_{\mathrm{i}}$ is a mispricing term; $\beta_{\mathrm{Ei}}$ is the $\mathrm{BHC}^{\prime}$ s equity beta that measures the sensitivity of its excess returns to the market equity premium; $\mathrm{R}_{\mathrm{mt}}$ is the monthly return on the overall market portfolio; and $\varepsilon_{\text {it }}$ is an error term.

\footnotetext{
${ }^{15}$ For BHCs, the Tier 1 capital ratio is the ratio of core capital elements (less goodwill and other intangible assets) to risk-weighted assets with respect to the Basel Capital Accord. The Reserve Banks' ratio of 10.4 percent in 2003 was determined within the PSAF with respect to their imputed assets and capital.
} 
For this study, we extended the benchmark model by incorporating two additional variables. First, since BHCs are particularly sensitive to the interest-rate environment, we included an interest-rate factor. Specifically, since banks typically borrow funds with short maturities and lend funds with longer maturities, we used a term premium, defined as the difference between long-term and short-term Treasury rates, as our interest-rate factor. Second, since we are concerned with BHCs' participation in the payments business, we introduced a proxy for BHC payments revenues into the model by interacting it with the two systematic factors. The four-factor model we estimated was

$$
\mathrm{R}_{\mathrm{it}}-\mathrm{R}_{\mathrm{ft}}=\alpha_{\mathrm{i}}+\left(\beta_{\mathrm{Ei}}+\beta_{\mathrm{EPi}} \mathrm{PRS}_{\mathrm{it}}\right)\left(\mathrm{R}_{\mathrm{mt}}-\mathrm{R}_{\mathrm{ft}}\right)+\left(\beta_{\mathrm{Ri}}+\beta_{\mathrm{RPi}} \mathrm{PRS}_{\mathrm{it}}\right)\left(\mathrm{R}_{\mathrm{Lt}}-\mathrm{R}_{\mathrm{St}}\right)+\varepsilon_{\mathrm{it}},
$$

where PRS it is the individual BHC's merger-adjusted payments revenue share; $R_{L t}$ is the constant maturity, ten-year Treasury yield; and Rst is the constant maturity, three-month Treasury yield.

Generating a proxy for BHC payments revenue is not a simple matter, since there are no standardized accounting definitions available. In this paper, we generated the PRS it variable using the definition of BHC payments revenues used by Rice and Stanton (RS, 2003), which followed on the work of Radecki (1999). Constructed using bank-level data that first became available in 2001, the RS measure is based on five revenue categories: service charges on deposit accounts; foregone interest revenue; payments-related credit card revenue; ATM fees; and payments-related trust revenues. Of course, such a payments revenue measure includes more than just wholesale payments business. Also, payments tend to be a loss leader. For these reasons, this measure is likely to be imprecise for the purposes of our analysis. To create the necessary five years of data for our study, we made further assumptions that unfortunately included ignoring the latter two categories entirely because of data limitations. In contrast, service charges on deposit accounts and foregone interest revenue were constructed historically, as per the RS study, since the required data were available. ${ }^{16}$

However, payments-related credit card revenue was calculated differently because of data limitations. We were able to use the RS definition for BHCs' payments-related credit card

\footnotetext{
${ }^{16}$ We use the Y9-C variable BHCK4483 for service charges on deposit accounts.
} 
revenues that were on-balance-sheet. That number was 17 percent of on-balance-sheet credit card revenues, where the percentage is derived from the payments-related fees charged by Master Card and Visa as 17 percent of issuer revenues in 1999.17 These fees consist of 14 percent of revenues due to interchange fees, 2 percent from annual fees, and 1 percent from enhancements. This parameter should be stable, since interchange fees have not changed much over time. For off-balance-sheet credit card revenues, the RS study used data on securitized credit card receivables that are only available starting in 2001, so we unfortunately ignored them for our PRSit variable.

BHCs receive compensation for their payment services not simply through explicit account maintenance and activity fees, but also because depositors forgo market interest rates on certain account balances. Depositors typically earn little or no interest on deposits in demand, negotiable order of withdrawal (NOW), savings, and money market accounts at banks. However, banks benefit by reinvesting these funds at market rates. Radecki (1999) found this implicit income to be approximately three times the explicit fees collected on these accounts. Following Radecki (1999) and Rice and Stanton (2003), we calculated foregone interest revenue by assuming that all deposits are invested at the federal funds rate, and that the bank "earns" the spreads between the federal funds rate and the average interest rates paid to various depositors. We calculated foregone interest revenue (FIR) as:

$$
\mathrm{FIR}_{\mathrm{it}}=\mathrm{DDA}_{\mathrm{it}}{ }^{*} \mathrm{f}_{\mathrm{t}}+\mathrm{MMDA}_{\mathrm{it}}{ }^{*}\left(\mathrm{f}_{\mathrm{t}}-\mathrm{rMMDAt}_{\mathrm{t}}\right)+\mathrm{NOW}_{\mathrm{it}}{ }^{*}\left(\mathrm{f}_{\mathrm{t}}-\mathrm{rNOW}_{\mathrm{t}}\right),
$$

where DDAit denotes a BHC's quarterly aggregate balance in demand deposit accounts; $\mathrm{ft}_{\mathrm{t}}$ is the average federal funds rate in quarter t; MMDA it is a BHC's quarterly aggregate deposits in money market accounts; rMMDAt is the national average money market rate for the year; NOW it is a BHC's quarterly aggregate deposits in NOW accounts; and rNowt is the national average rate on NOW accounts for the year. ${ }^{18}$ The deposit rates are national averages for the last week of the

\footnotetext{
${ }^{17}$ The measure of on-balance-sheet credit card revenues we used was RIAD4054 up to the end of 2000 and RIADB485 from the first quarter of 2001. Both variables consist of all interest, fees, and similar charges levied against or associated with all extensions of credit to individuals for household, family, and other personal expenditures arising from credit cards and related plans in domestic offices, but excluding annual or other periodic fees paid by holders of credit cards issued by the bank.

${ }^{18}$ The variable DDAit is the Y9-C variable BHCB2210. The variable NOW it denotes the balance in "negotiated order of withdraw" accounts as defined by the Y9-C variable BHCB2389. The variable MMDAit is the Y9-C variable BHCB2389.
} 
year as reported in the Bank Rate Monitor. These quarterly series were made monthly for our regression analysis using simple interpolation.

The payments-revenue variable used in the RS study was the sum of the various payments revenues divided by operating revenues. For our calculations, quarterly BHC operating revenue is defined as the sum of total noninterest income and total interest income minus total interest expense and provisions for credit losses. ${ }^{19}$ Note that foregone interest revenues are not included in the definition of operating revenue, and thus our payments revenue share variable, denoted as $P R S_{i t}$, should be considered a normalized measure of payments revenue and not a simple percentage.

As shown in Table 3, our normalized payments revenue variable has fluctuated over the sample period. Averaging across the BHCs in the largest peer group, the PRS it variable has declined from a high of 57 percent in 1999 to 27 percent in 2003. The decline has been driven mainly by the decline in foregone interest revenue, which in turn is mainly driven by the level of the federal funds rate. The important decline in that rate since 2000 clearly induced a decline in our PSR it variable. ${ }^{20}$

To estimate the CAPM specifications we are interested in, we used both individual BHC regressions and panel-data techniques. As noted by Barnes and Hughes (2001), panel-data estimation provides more precise CAPM parameter estimates by taking account of any information available in cross-sectional stock return data. Within the panel-data framework, we estimated a random effects model, which yields single parameter estimates representative of all peer group BHCs. ${ }^{21}$

To distinguish which specifications were preferred from a statistical point of view, we used both model selection criteria and hypothesis testing criteria. We used the Akaike information criterion (AIC) and the Bayesian information criterion (BIC), for both of which lower values indicate the best combination of in-sample fit and parameter parsimony. To

\footnotetext{
${ }^{19}$ We use the Y9-C variables BHCK4079, BHCK4107, BHCK4073, and BHCK4230, respectively.

${ }^{20}$ These numbers are arguably large and point to the imprecision with which this variable may be measured.

21 With regard to the panel regession analysis, we estimated specifications including fixed effects, random effects, and random effects with no constant. Standard specification tests indicated that the random effects model was the appropriate one to use for our data, and we present only our results for this specification.
} 
evaluate the model selection criteria across the BHCs in our peer groups, we calculated both their averages and frequency distributions. For the hypothesis testing criteria, we combined the individual hypothesis testing results across the peer group BHC regressions, using the percentage of the individual peer group BHC regressions in which the null hypothesis was rejected at the 5 percent significance level, as well as the Pearson $\mathrm{p}_{\lambda}$ test. $^{22}$

In addition to these statistical criteria, we also evaluated the alternative model specifications to see whether their fitted values were statistically different from one another. This third approach provides statistical judgment as to whether there are material differences across the specifications. The different conclusions developed by these criteria permit us to determine the most appropriate statistical model that contributes in a material way relative to the more parsimonious, benchmark CAPM. That is, if the differences between the fitted values are statistically indistinguishable from zero on average, the benchmark model should be the preferred model.

As shown in Table 4, we examined seven specifications of the CAPM, and the model selection criteria were averaged across the 47 BHCs in the "top 50" peer group, as estimated over the period 1999 to 2003. For both the AIC and BIC criteria, the benchmark CAPM provides the best combination of in-sample fit and parameter parsimony. Model rankings across the 47 individual BHC regressions tell a similar story; the benchmark CAPM has the lowest AIC across 23 BHCs and the lowest BIC for 38 firms. The next best performing models were M2 (that is, the model with the two systematic factors), M3 (the two-factor model with the market factor and the market factor interacted with the PRSit variable), and M4 (the three-factor model with the market factor alone and both systematic factors interacted with PSR it). The results of the hypothesis testing also suggest that the benchmark model is the most appropriate here. From Table 5, it is evident that across the 47 likelihood ratio tests for each of the six hypotheses, the rejection frequency is never greater than 12.8 percent. Since the first hypothesis of interest

\footnotetext{
${ }_{22}$ The Pearson $\mathrm{p}_{\lambda}$ test is used to combine the results of independent tests into an overall rejection (or non-rejection) of the null hypothesis. Suppose there are k cases, and let $\mathrm{p}_{\mathrm{i}}$ be the probability in case i of obtaining an estimated coefficient as high as the one that would be obtained if the null hypothesis were true. The $\mathrm{p}_{\lambda}$ statistic is the sum for all $\mathrm{k}$ tests of $-2 \ln \left(\mathrm{p}_{\mathrm{i}}\right)$, and it has a chi-squared distribution with 2k degrees of freedom; see Maddala (1977), pp. 47-48.
} 
corresponding to the benchmark model (that is., that the coefficients of the three additional factors are jointly zero) was accepted for about 90 percent of the "top 50" peer group, we advocate selecting the benchmark model. Combining the 47 test results for each hypothesis using the Pearson $\mathrm{p}_{\lambda}$ test, we again conclude that the benchmark model should be selected.

In terms of the distributional analysis of the specifications' fitted values, it would be most interesting to see whether the distributions for M1, M2, M3, and M4 were statistically different from one another. Yet, since the statistical criteria strongly suggest that the benchmark model is preferred, consideration of the "materiality" criterion seems redundant. We present these additional in-sample results simply for completeness. Table 6 presents distribution analysis results for the medians and the full distributions of the 2,820 (that is, 47 firms x 60 months) fitted values from our seven CAPM specifications. The medians for M4 and M7 were statistically different from that of the benchmark market model at the 5 percent significance level. Comparisons of the entire distributions of the fitted values, however, do not suggest a statistical difference between the benchmark model and the other specifications. Hence, according to our overall decision criteria, although there may be weak evidence in support of an alternative CAPM specification, the benchmark model is the best choice for our exercise, based on the individual regressions. ${ }^{23}$

Turning to the panel regression results shown in Table 7, the preferred models are M7 (the full specification) according to the AIC criterion and M4 (that is, the three-factor model with the market factor alone and both systematic factors interacted with PSR $\mathrm{it}_{\mathrm{i}}$ ) according to the BIC criterion. The hypothesis testing criteria presented in Table 8 also suggests that M7 is the most appropriate model, since all of the parameter restrictions were rejected. Regarding the materiality criterion results for both the medians and full distributions of the fitted values, Table 9 shows that M4, M6, and M7 are statistically different from the benchmark model, while M5 is also different, but just for the median analysis. Thus, the overall in-sample panel results for the “top 50" peer group suggest that M4 and M7 are the most appropriate specifications and are materially different from the benchmark CAPM. Hence, the evidence using panel estimation methods stands in stark contrast to the evidence using individual regressions.

\footnotetext{
${ }^{23}$ Specification analysis based on our three other peer groups resulted in the same conclusion.
} 
To examine the contrasting results from these two estimation types further, we compared the three sets of fitted values to determine whether their differences were material. In other words, we examined whether the 2,820 fitted values for the benchmark model, estimated using individual regressions, were materially different from those for M4 and M7 estimated using the panel-data estimation method. The medians for the panel M4 and M7 specifications were statistically different from that of the benchmark model, with p-values of around 0.02. However, the distributions were not significantly different, with p-values of 0.24 and 0.27 for M4 and M7, respectively. Thus, our in-sample materiality criteria suggest that the panelregression framework does not provide a compellingly material improvement from the benchmark CAPM single-equation ordinary least squares (OLS) regression approach. Furthermore, since panel estimation methods are not commonly used in industry or academic practice for calculating COE estimates, this estimation approach would not be appropriate for generating the Reserve Banks' COE estimates.

In summary, our in-sample specification tests and comparison of estimation procedures suggest that the benchmark CAPM, based on individual regressions, is the most appropriate for our exercise. In the section that follows, we examine more directly the non-nested questions of peer-group effects and further adjustments based on firm-specific factors.

Based on our analysis so far, we propose to generate COE estimates for the Reserve Banks' payments business by estimating separate time-series regressions for the BHCs in our chosen peer groups using OLS estimation. For comparison purposes, we performed a parallel analysis using panel regression techniques, where possible. For the benchmark CAPM, the individual market equity betas were aggregated up to a single value using an average; that is.,

$$
\beta_{\mathrm{E}, \mathrm{FED}}=\sum_{\mathrm{i}=1}^{\mathrm{K}} \mathrm{w}_{\mathrm{i}} \beta_{\mathrm{Ei}},
$$

where $\mathrm{K}$ is the number of BHCs in the peer group. What weights should be used in our calculations? As discussed by Green et al. (2003), equal weights and weights based on market capitalization (that is, value weights) are the leading candidates. For this exercise, equal weights 
were chosen, since the candidate peer groups, beyond the first two, are based on BHC-specific variables. $^{24}$

\section{Non-Nested Comparison of COE Estimates}

The empirical results presented in the prior section focused on CAPM specification issues for the full peer group of 47 publicly traded BHCs within the list of top 50 BHCs sorted by deposits as of year-end 2003. The analysis was based on issues of in-sample fit and model selection criteria, which are appropriate for examining nested model alternatives. In this section, we focus on COE estimates generated across the non-nested alternative methods just discussed. The specific questions that we focus on are:

- What impact do adjustments for firm-specific factors, such as firm leverage and lineof-business concentration, have on the COE estimates for the Reserve Banks' payments business?

- What impact does narrowing the peer group have on these COE estimates?

\subsection{Incorporating Firm-Specific Factors into the COE Estimates}

As summarized in various financial textbooks, methodologies have been developed to adjust equity betas for firm-specific factors. In particular, balance-sheet leverage has been acknowledged as an important factor affecting the sensitivity of firms' stock returns to general market fluctuations. Leverage is more important for banks than for commercial firms, since deposits and other sources of short-term funding are used to finance a much larger balance sheet of loans and other longer-term investments; see Wilson (2002, 2003). As originally suggested by Hamada (1972) and summarized in various textbooks, firms' equity betas within the benchmark CAPM can be adjusted for leverage and tax exposures to generate betas for firms' underlying assets using the following equation:

\footnotetext{
${ }^{24}$ Note that the choice of weighting scheme is material to the COE analysis, but we chose equal weights in order to better account for BHC-specific variables.
} 


$$
\beta_{\mathrm{A}, \mathrm{i}}=\beta_{\mathrm{Ei}}\left(1+\left(1-\tau_{\mathrm{i}}\right)\left(\frac{\mathrm{D}}{\mathrm{E}}\right)_{\mathrm{i}}\right)^{-1},
$$

where $\beta_{\mathrm{Ai}}$ is the asset beta for BHC $\mathrm{i} ; \beta_{\mathrm{Ei}}$ is its equity beta; $\tau_{\mathrm{i}}$ is its marginal tax rate; and (D/E)i is the BHC's book value debt-to-equity ratio.

For our exercise, we generated the releveraged asset beta for the Reserve Banks' payments business, denoted $\beta_{\mathrm{RA}, \mathrm{FED}}$, by averaging the individual asset betas for the $\mathrm{BHC}$ peer group and releveraging; that is,

$$
\beta_{\mathrm{RA}, \mathrm{FED}}=\left(1+\left(1-\tau_{\mathrm{FED}}\right)\left(\frac{\mathrm{D}}{\mathrm{E}}\right)_{\mathrm{FED}}\right) \sum_{\mathrm{i}=1}^{\mathrm{K}} \beta_{\mathrm{Ai}} / \mathrm{K} .
$$

To implement this leverage adjustment, several empirical questions regarding the $\mathrm{D} / \mathrm{E}$ ratio need to be addressed. The first question is related to the appropriate definition of BHC debt. We based our comparison of COEs on the usual definition of total debt, which excludes deposits. In principle, we could have used total liabilities in our analysis, since they are integral to our definition of the peer groups, but we chose to be consistent with industry and academic practice. The second question regards how the debt and equity are to be valued. We used book values, instead of market values, mainly because the Reserve Banks do not have observable market values for their imputed levels of debt and equity. The third question is what values to use for the Reserve Banks' parameters for these calculations. We used the 2003 median values for the reference peer group, as reported in Compustat. The imputed D/E ratio for the Reserve Banks was 2.68 when using total debt, and the imputed marginal tax rate was 33 percent. ${ }^{25}$

As further discussed by Wilson $(2002,2003)$, equity cost of capital varies in important ways across business lines within the financial services industry. These variations could be important for our analysis, especially since the payments business is not the primary activity of the peer group BHCs, and that activity is not in the types of payments businesses that the Reserve Banks engage in. To address these concerns, researchers have developed adjustments to

\footnotetext{
25 An alternative measure of the D/E ratio is to use the assumptions in place for other sections of the PSAF calculations. Under those assumptions, the Reserve Banks' payments business holds 95 percent debt and 5 percent equity, which is the minimum amount required to be considered well capitalized under the prompt corrective action guidelines of FDICIA. However, this implied D/E ratio of 19 is in the extreme upper tail of the 2003 sample distribution and would lead to results that were not representative of the chosen peer groups.
} 
equity betas based on a firm's business line concentrations. These so-called "line-of-business" betas were proposed by Ehrhardt and Bhagwar (1991) and refined by Kaplan and Peterson (1998) and Cummins and Phillips (2003). The underlying premise is that a firm is a portfolio of businesses, and the firm's beta is then a weighted average of the separate businesses' beta coefficients. In theory, the weight on each line-of-business beta is the ratio of the market value of the business to the market value of the firm as a whole. Since the market values of the individual businesses typically can not be observed, a proxy measure must be used for the decomposition. Usually, an accounting measure, such as sales or revenues, is used.

For this study, we use our payments revenue share (PSR it) variable, which is the ratio of our defined payments revenues to total operating revenues, as the appropriate proxy for $2003 .{ }^{26}$ The line-of-business adjustment to the standard equity beta is performed as a regression of the peer groups' equity betas as of year-end 2003 on our payments revenue share variable and its complement; that is,

$$
\beta_{\mathrm{E}, \mathrm{i}}=\beta_{\mathrm{E}, \mathrm{LOB}} \mathrm{PRS}_{\mathrm{i}}+\beta_{\mathrm{R}, \mathrm{LOB}}\left(1-\mathrm{PRS}_{\mathrm{i}}\right)+\varepsilon_{\mathrm{i}},
$$

where $\beta_{\mathrm{E}, \mathrm{LOB}}$ is the adjusted equity beta for the payments business and $\beta_{\mathrm{R}, \mathrm{LOB}}$ is the adjusted equity beta for all other BHC business. For our analysis, $\beta_{\mathrm{E}, \mathrm{LOB}, \mathrm{FED}}=\beta_{\mathrm{E}, \mathrm{LOB}}$. The sample sizes of these cross-sectional regressions change across peer groups, ranging from 47 for the "top 50" peer group to just 4 for the global processors peer group. Clearly, the latter regression is not statistically sound, and, even for the larger peer group, we generated $\beta_{\mathrm{E}, \mathrm{LOB}}$ values that were insignificantly different from zero. Our rationale for examining such estimates is consistency of approach, especially since such limitations are common across the cases we examined.

In the above-mentioned papers, equity betas, as opposed to asset betas, are decomposed into line-of-business betas. Cummins and Phillips (2003) specifically mention that they worked with equity betas because the assumption that all divisions within a firm have the same leverage is too strong within the insurance industry that they examine. Although this may be

\footnotetext{
${ }^{26}$ Recall that the PRS it variable is not a strict percentage, but a normalized value. However, since this variable should be highly correlated with the true payments revenue shares, we used it for our line-of-business regressions. For this study, we effectively divide the peer group BHCs into just two business lines: payments and non-payments activities. This coarse division might be improved by including other revenues, such as revenues from lending.
} 
true for BHCs, we chose to examine the impact of the line-of-business adjustment on both equity and asset betas, as per Damodaran (2001), and thus on our COE estimates. The asset beta regression was conducted as:

$$
\beta_{\mathrm{A}, \mathrm{i}}=\beta_{\mathrm{A}, \mathrm{LOB}} \mathrm{PRS}_{\mathrm{i}}+\beta_{\mathrm{R}, \mathrm{LOB}}\left(1-\mathrm{PRS}_{\mathrm{i}}\right)+\varepsilon_{\mathrm{i}} .
$$

The releveraged asset beta with the line-of-business adjustment for the Reserve Banks' payments business is thus:

$$
\beta_{\mathrm{RA}, \mathrm{LOB}, \mathrm{FED}}=\left(1+\left(1-\tau_{\mathrm{FED}}\right)\left(\frac{\mathrm{D}}{\mathrm{E}}\right)_{\mathrm{FED}}\right) \beta_{\mathrm{A}, \mathrm{LOB}} .
$$

Note that, as written above, these line-of-business regressions give equal weight to all firms in the peer group, and hence the estimated coefficients are representative of the average firm in the peer group. In contrast, market capitalization weights could be introduced into the regression to generate coefficients that are representative of the peer group as a whole.

For the benchmark CAPM, the COE estimate for a given year and adjustment type $\mathrm{X}$ is

$$
\mathrm{COE}_{\mathrm{X}, \mathrm{FED}}=\mathrm{R}_{\mathrm{F}}+\beta_{\mathrm{X}, \mathrm{FED}} \mathrm{E}\left[\mathrm{R}_{\mathrm{M}}-\mathrm{R}_{\mathrm{F}}\right] \text {, }
$$

where $R_{F}$ is the one-year risk-free rate and $E\left[R_{M}-R_{F}\right]$ is the annualized, expected market risk premium, which is commonly used as a proxy for a long-term average value. The four adjustment types we considered were: no adjustment (that is, $\mathrm{X}=\mathrm{E})$, a leverage adjustment $(\mathrm{X}=$ $\mathrm{RA})$, a line-of-business adjustment $(\mathrm{X}=\mathrm{E}, \mathrm{LOB})$, and an adjustment for both factors $(\mathrm{X}=$ RA,LOB).

For our analysis, we chose to examine COE estimates from the alternative CAPM specifications discussed earlier. Even though the in-sample criteria suggested the benchmark model, we examined the impact of all the specifications on the COE estimates. However, when considering multifactor CAPMs, some conceptual and practical difficulties arise. First, the additional factors must be accounted for in the COE estimates; that is,

$$
\mathrm{COE}_{\mathrm{E}, \mathrm{m}, \mathrm{FED}}=\mathrm{R}_{\mathrm{F}}+\sum_{\mathrm{k}_{\mathrm{m}}} \beta_{\mathrm{k}, \mathrm{FED}} \mathrm{f}_{\mathrm{k}}
$$

where COEE,m,FED is the Reserve Banks' COE estimate based on the CAPM estimation framework for model specification $\mathrm{m}$ with $\mathrm{k}_{\mathrm{m}}$ factors; $\beta_{\mathrm{k}, \mathrm{FED}}$ is the average estimate of BHC stock return 
sensitivity to the $\mathrm{k}^{\text {th }}$ factor in that specification; and $f_{k}$ is the long-term average value of the $\mathrm{k}^{\text {th }}$ factor proxying for its expected value. ${ }^{27}$

Second, to our knowledge, the problem of introducing capital structure into these multifactor models has not been resolved in the academic literature or in industry practice. The main difficulty is how best to adjust the estimated values using the peer groups' and the Reserve Banks' D/E ratios and tax rates. For this component of our analysis, we chose to apply the leverage adjustment presented earlier directly to the COE estimates themselves. ${ }^{28} \mathrm{We}$ generated

$$
\mathrm{COE}_{\mathrm{RA}, \mathrm{m}, \mathrm{FED}}=\left(1+\left(1-\tau_{\mathrm{FED}}\right)\left(\frac{\mathrm{D}}{\mathrm{E}}\right)_{\mathrm{FED}}\right) \sum_{\mathrm{i}=1}^{\mathrm{K}} \mathrm{COE}_{\mathrm{RA}, \mathrm{m}, \mathrm{i}} / \mathrm{K},
$$

where COERA,m,i is the leverage-adjusted COE estimate for a given BHC based on CAPM specification $\mathrm{m}$; that is,

$$
\mathrm{COE}_{\mathrm{RA}, \mathrm{m}, \mathrm{i}}=\left(1+\left(1-\tau_{\mathrm{i}}\right)\left(\frac{\mathrm{D}}{\mathrm{E}}\right)_{\mathrm{i}}\right) \mathrm{COE}_{\mathrm{E}, \mathrm{m}, \mathrm{i}}
$$

where COEE,m,i is the unadjusted COE estimate for a given BHC as implied by specification m.

Finally, to introduce the line-of-business adjustment for multifactor CAPMs, we again apply the adjustments to the firm-level COE estimates. To apply this adjustment alone, we estimated the regression

$$
\mathrm{COE}_{\mathrm{E}, \mathrm{m}, \mathrm{i}}=\mathrm{COE}_{\mathrm{E}, \mathrm{m}, \mathrm{LOB}} \mathrm{PRS}_{\mathrm{i}}+\mathrm{COE}_{\mathrm{ER}, \mathrm{m}, \mathrm{LOB}}\left(1-\mathrm{PRS}_{\mathrm{i}}\right)+\varepsilon_{\mathrm{i}},
$$

using the 2003 COE estimates based on the different CAPM specifications. The estimate for the Reserve Banks, denoted COEE,m,LOB,FED, is just COEE,m,LOB. To adjust the COE estimates for both business concentration and leverage effects, we estimated the regression

$$
\mathrm{COE}_{\mathrm{RA}, \mathrm{m}, \mathrm{i}}=\mathrm{COE}_{\mathrm{RA}, \mathrm{m}, \mathrm{LOB}} \mathrm{PRS}_{\mathrm{i}}+\mathrm{COE}_{\mathrm{RR}, \mathrm{m}, \mathrm{LOB}}\left(1-\mathrm{PRS}_{\mathrm{i}}\right)+\varepsilon_{\mathrm{i}}
$$

on the individual deleveraged COE estimates and then releveraged COERA,m,LOB such that

\footnotetext{
${ }^{27}$ For our calculations, the average market risk premium value was 8.25 percent; the average term premium was 1.25 percent; the average interaction between PRS and the market premium was 3.45 percent; and the average interaction between PRS and the term premium was 0.52 percent.

${ }^{28}$ We thank Franklin Allen for suggesting this approach.
} 


$$
\mathrm{COE}_{\mathrm{RA}, \mathrm{m}, \mathrm{LOB}, \mathrm{FED}}=\left(1+\left(1-\tau_{\mathrm{FED}}\right)\left(\frac{\mathrm{D}}{\mathrm{E}}\right)_{\mathrm{FED}}\right) \mathrm{COE}_{\mathrm{RA}, \mathrm{m}, \mathrm{LOB}} .
$$

Table 10 provides summary statistics for the COE estimates without adjustments (that is, $\mathrm{X}=\mathrm{E})$ as generated by the seven models across the 47 individual CAPM regressions. A striking feature of these results is the presence of negative values. These values also appear for the other three adjustment types, especially for those adjusted for line-of-business concentration (that is, $\mathrm{X}=\mathrm{E}, \mathrm{LOB}$ and $\mathrm{RA}, \mathrm{LOB})$. The primary drivers behind these negative $\mathrm{COE}$ estimates are parameter estimates, either in the CAPM specification or in the second-stage, line-of-business regressions, that are negative but not statistically different from zero. Aside from being statistically insignificant, these parameter estimates could be negative for econometric reasons ranging from possible multicollinearity to the construction of the PRS it variable. To address these concerns, we conducted our analysis on the sample of all the generated COE estimates as well as on a sample that truncates negative values at zero (that is, negative values are replaced with zeros). ${ }^{29}$

\subsection{Comparison Across Firm-specific Adjustments to the COE Estimates}

The primary question analyzed in this section is whether incorporating additional firmlevel variables, particularly leverage and business concentrations, has a substantive statistical impact on the COE estimates for the Reserve Banks' payments business, and hence on the PSAF. Recall that the four adjustment types we consider are: no adjustment, a leverage adjustment, a line-of-business adjustment, and both adjustments applied concurrently. For our analysis, we tested the hypothesis that the differences in COE estimates relative to the benchmark case with no adjustments averaged to zero; that is, that the additional firm-level variables do not have a statistically significant impact on COE estimates.

For each comparison, we have 28 observations, generated by the seven model specifications for the four peer groups for all four firm-specific adjustment types. Note that

\footnotetext{
${ }^{29}$ As noted above, there could be also be issues regarding the measurement of the PRS variable.
} 
initially we do not examine COE estimates generated using the panel-regression approach, because this methodology generates beta estimates common across the peer-group BHCs and hence precludes our line-of-business analysis. The comparison is conducted by regressing the above $28 \mathrm{COE}$ differences on a constant and controls for model specification and peer group. Note that robust standard errors are estimated using the Huber/White sandwich technique to account for any dependence across the COE estimates.

The empirical results suggest that we cannot reject the null hypothesis that the leverage adjustment is relevant. The difference in these COE estimates from the benchmark values is significantly different from zero with a robust p-value of 0.08 . However, the differences between the benchmark equity COE estimates and those adjusted for business concentration alone and with a leverage adjustment are not significantly different from zero, with robust pvalues of 0.71 and 0.56 , respectively. Taken at face value, this would imply that while the

leverage adjustment is material, the adjustments for business concentration and simultaneously for leverage and business concentration are immaterial.

To focus more directly on the leverage adjustment alone, we can now include the COE estimates generated by the panel-regression estimation in our analysis. Hence, the sample of COE estimates available for analysis doubles to 56, and it can be increased by a further 28 observations if we consider the COEЕ,m,LOB estimates (that is, again seven CAPM specifications and four peer groups). For both of these sets of estimates, we reject the null hypothesis that the COE differences are statistically different from zero, with robust p-values of 0.53 and 0.95 , respectively. Hence, the results based on these larger samples of alternative COE estimates suggest that the leverage adjustment is not statistically meaningful for our exercise. This conclusion also obtains when we consider the sample with truncation of negative COEs at zero.

\subsection{Comparison Across Peer Groups}

As discussed previously, selection of a BHC peer group for the Reserve Banks' payments business is a challenge for several reasons. In our analysis here, the largest peer group, consisting of the 47 publicly traded BHCs in the list of top 50 by deposits as of year-end 2003, was our benchmark peer group. We examined whether narrowing the peer group using certain 
economic criteria had a material impact on the needed COE estimate. The answer to this question was not clear a priori, but in fact, our empirical results suggest that these reductions are not material.

The analytical method used was again to examine the differences between COE estimates for the benchmark and three alternative peer groups. We have a total of $42 \mathrm{COE}$ estimates, including 28 observations for the estimation using individual regressions (that is, seven CAPM specifications and four firm-level adjustment types) and 14 observations for the panel-regression estimation, since the line-of-business adjustments cannot be applied here [7 model specifications * 2 adjustment types (E and RA)]. For each alternative peer group, we examined whether the differences between their 2003 COE estimates and the benchmark values were statistically different, using a regression of these differences on a constant and control variables for the chosen specification and the firm-level adjustments used. ${ }^{30}$

The COE differences for the Reserve Bank-like and global processor peer groups relative to the benchmark peer group are not statistically significant, with p-values of 0.10 and 0.48 , respectively. However, the differences for the top 25 peer group are statistically significant, with a p-value of 0.01 , an average difference of 3.89 percent, and a standard deviation of 9.32 percent.

Why is the top 25 peer group different from the two alternative samples? The main driver was line-of-business regressions that generated some unlikely results (that is, large negative values), usually due to negative and insignificant parameter estimates. The results without line-of-business COE estimates compared 28 observations [that is, 7 specifications * 2 estimation methods * 2 adjustment types (E and RA)] and showed that the COE differences across the peer groups were not significantly different from zero, with p-values of $0.35,0.68$ and 0.18 for the global processors, the Reserve Bank-like peer group, and the top 25 by deposits peer group, respectively. Similarly, for the truncated sample of the full 42 COE estimates, the average differences between the benchmark values and the values of the three other peer groups were never significantly different from zero, with p-values of $0.54,0.66$, and 0.14 , respectively. These

\footnotetext{
30 As before, the regressions are run with robust standard errors. For the sake of brevity, the p-values on the estimated coefficients on the control variables are not included. They are available upon request.
} 
results lead to the conclusion that peer-group effects are not a significant factor in our calculations.

In summary, the selection of the peer group does not have much impact on the COE estimates for the Reserve Banks' payments business, particularly if one discounts the negative COE estimates arising from insignificant, but negative, parameter estimates. Given the challenges in crafting the appropriate peer group for this exercise in a way that is replicable by the public, the simple criterion of the publicly traded BHCs in the list of top 50 BHCs by deposits is reasonable. Further narrowing the peer group based on additional criteria might have certain benefits, but, at least for the reductions examined here, they do not materially affect the COE calculations, and hence the PSAF, from a statistical point of view.

\section{Conclusions}

Fama and French (1997) conclude their study of estimates of equity capital costs with the following quote: "Our guess is that, whatever the formal approach, two of the ubiquitous tools in capital budgeting are a wing and a prayer, and serendipity is an important force in outcomes." Such a pessimistic evaluation of this type of operational exercise may be accurate, but equity capital costs must be calculated on an ongoing basis by a variety of firms, including the Federal Reserve Banks' payments business. Given this operational reality, we examined various alternative estimates of this cost of equity capital within the CAPM framework. Our goal was to determine which measures were the most appropriate to use for this exercise, at least in a relative sense.

Our estimation results suggest that introducing additional factors, such as changes in market interest rates and firms' payments revenue shares of operating revenue, do matter in a statistical sense; that is, their addition does improve the model's in-sample fit in a statistically meaningful way, particularly with panel-regression techniques. However, our nested model selection, hypothesis testing, and materiality criteria suggest that these additional factors are statistically immaterial. Similarly, for peer group issues, unless there are strong priors on how to conduct the beta estimation, the estimated COEs are generally not materially different across peer-group specifications. Across beta and COE-adjustment types, incorporating additional 
firm-level data into the beta estimation process does not appear to change the results in statistically significant ways.

Given these results, we have found that the cost of equity capital and hence the PSAF for the Federal Reserve Banks' payments services can reasonably be estimated using the simple CAPM. There is no compelling evidence that suggests it would be better to extend the model to account for additional model factors, for firm leverage, or for business concentration, as these extensions do not lead to material differences in the estimated cost. ${ }^{31}$

Of course, based on our criteria, since the different peer groups (and adjustment types) do not lead, on average, to statistically different COEs, one could choose whichever method was simplest or easiest to implement (for example, no adjustment to beta, OLS estimation, M1, and the Global Processors peer group, since then one would only need to collect data on four BHCs). We do not intend to imply, however that there will not be economically significant differences in the results between any two particular combinations of model, peer group, adjustment type, and estimation type chosen. There most likely will be economic differences.

To conclude, using the benchmark CAPM with the largest peer group generates a COE and PSAF estimate that is not materially improved upon by adding more factors into the CAPM specification, by using panel regression methods, by narrowing the peer group, or by adjusting for leverage and/or business concentration. The reason for this may be that the COE estimates from the CAPM method are not materially affected by these refinements or that they are unavoidably imprecise, as per Fama and French. Either way, if you need COE estimates and you choose the popular CAPM approach, the simplest of calculation methods will provide an appropriate estimate. Of course, this is an empirical exercise, and the results could change over time. Also, as a longer history on payments-related data emerges from the Y-9C collection process, our estimates of payments revenue share may improve over time, perhaps further reducing any estimation noise.

\footnotetext{
31 It is interesting to note that several textbooks discuss the idea of combining a firm's current equity beta estimate with the value of 1 in order to generate a more widely acceptable measure; see Damodaran (2001). Actually, it may be the case of the textbooks describing industry practice, since Bloomberg-reported equity betas place a two-thirds weight on estimated betas and a one-third weight on the value 1. As noted earlier, as of October 2005, the Federal Reserve System has decided to proceed with a beta value of 1; see Board of Governors of the Federal Reserve System (2005).
} 


\section{References}

Barnes, M.L., and A.W. Hughes. 2001. "Conditional Beta Estimation and Forecasting with Panel Data Methods." Manuscript, Federal Reserve Bank of Boston.

Board of Governors of the Federal Reserve System. 1990. "The Federal Reserve in the Payments System." Federal Reserve Bulletin 76(5) May: 293-298.

Bower, D.H., R.S. Bower, and D.E. Logue. 1984. “Arbitrage Pricing Theory and Utility Stock Returns." Journal of Finance 39(4): 1041-1054.

Bruner, R.F., K.M. Eades, R.S. Harris, and R.C. Higgins. 1998. “Best Practices in Estimating the Cost of Capital: Survey and Synthesis." Financial Practice and Education 8:13-28.

Committee on the Federal Reserve in the Payments Mechanism. 1998. The Federal Reserve in the Payments Mechanism. Washington, D.C.: Federal Reserve System.

Cummins, J.D., and R.D. Phillips. 2003. "Estimating the Cost of Equity Capital for PropertyLiability Insurers.” Working paper 03-17. The Wharton Financial Institutions Center.

Damodaran, A. 2001. Corporate Finance: Theory and Practice. New York: John Wiley \& Sons, Inc.

Division of Federal Reserve Bank Operations, Board of Governors of the Federal Reserve System. 1983. "Private Sector Adjustment Factor for 1984." Federal Register 202 October 18: 48288-48295 [Docket No. R-0485].

Ehrhardt, M.C., and Y.N. Bhagwat. 1991. “A Full-Information Approach for Estimating Divisional Betas." Financial Management 20(2): 60-69.

Eisenmenger, R.W., W.C. Conrad, J.R. Kudlinski, T.E. Ormiston, B.R. Rawlings, T.J. Salvaggio, and B. Wolkowitz. 1980. "Report of the Pricing Task Force on the Private Sector Adjustment Factor." Manuscript, Board of Governors of the Federal Reserve System.

Fama, E.F., and K.R. French. 1997. "Industry Costs of Equity" Journal of Financial Economics 43(2) February: 153-193.

Fama, E.F., and K.R. French. 2004. “The Capital Asset Pricing Model: Theory and Evidence." Journal of Economic Perspectives 18(3) Summer: 25-46.

Gilbert, R.A., D.C. Wheelock, and P.W. Wilson. 2004. “New Evidence on the Fed's Productivity in Providing Payments Services." Journal of Banking and Finance 28(9) September: 21752190. 
Graham, J.R., and C.R. Harvey. 2001. "The Theory and Practice of Corporate Finance: Evidence from the Field." Journal of Financial Economics 60(2-3) May-June: 187-243.

Green, E., J.A. Lopez, and Z. Wang. 2003. “Formulating the Imputed Cost of Equity Capital for priced Services at Federal Reserve Banks." Federal Reserve Bank of New York Economic Policy Review 9(3): 55-81.

Hamada, R.S. 1972. "The Effect of the Firm's Capital Structure on the Systematic Risk of Common Stocks." Journal of Finance 27(2) May: 435-452.

Kaplan, P.D. and J.D. Peterson. 1998. "Full-Information Industry Betas" Financial Management 27(2): 85-93.

Maddala, G.S. 1977. Econometrics. New York: McGraw-Hill.

Quick, P.D., and S.C. Salop. 1985. "The Federal Reserve Cost of Capital: Methodologies for Estimating an Imputed Cost of Equity." Manuscript, Quick Finan and Associates.

Radecki, L. 1999. "Banks' Payments-Driven Revenues." Federal Reserve Bank of New York Economic Policy Review 5(2): 53-70

Rice, T., and K. Stanton. 2003. "Estimating the Volume of Payments-Driven Revenues." Emerging Payments Occasional Paper Series 2003-1C. Federal Reserve Bank of Chicago.

Thomson, J.B. 2001. "PSAF, Economic Capital and the New Basel Accord." Working Paper 01/11. Federal Reserve Bank of Cleveland.

U.S. Congress, House of Representatives, Committee on Banking, Finance and Urban Affairs and Committee on Government Operations. 1983. Role of the Federal Reserve in Check Clearing and the Nation's Payments System. 98 ${ }^{\text {th }}$ Congress, First session, June 15-16. Banking Committee Serial No. 98-36: 1011.

Vander Weide, J.H. 2004. Prepared Testimony for the Pacific Gas and Electric Company: Cost of Capital 2004 and 2005 Submission to the California Public Utilities Commission.

Wall, L. 1988. “Estimation of Target Return on Equity Using a Capital Asset Pricing Model.” Manuscript, Board of Governors of the Federal Reserve System.

Wilson, T. 2003. “Overcoming the Hurdle.” Risk. July: 79-83.

Wilson, T. 2002. “Overcoming the Hurdle: Integrating the Shareholder and Debtholder Perspectives." Manuscript, Mercer Oliver Wyman. 
Table 1. Bank holding companies in the "top $50 \mathrm{BHCs"}$ peer group

\begin{tabular}{|c|c|c|c|c|c|c|}
\hline \multicolumn{4}{|c|}{\begin{tabular}{|l|l} 
Rank & Peer Group Bank Holding Co
\end{tabular}} & \multirow{2}{*}{$\frac{\text { top 25 }}{X}$} & \multirow{2}{*}{$\frac{\text { R.Bank-like }}{\mathrm{X}}$} & \multirow[t]{2}{*}{ Glob. Proc. } \\
\hline 01 & CITIGROUP INC. & $13.81 \%$ & $19.05 \%$ & & & \\
\hline 02 & BANK OF AMERICA CORPORATION & $12.07 \%$ & $11.10 \%$ & $\mathrm{X}$ & & \\
\hline 03 & J.P. MORGAN CHASE \& CO. & $9.51 \%$ & $11.62 \%$ & $\mathrm{X}$ & $\mathrm{X}$ & \\
\hline 04 & WELLS FARGO \& COMPANY & $7.21 \%$ & $5.85 \%$ & $\mathrm{X}$ & $\mathrm{X}$ & \\
\hline 05 & WACHOVIA CORPORATION & $6.54 \%$ & $6.04 \%$ & $\mathrm{X}$ & $\mathrm{X}$ & \\
\hline 06 & BANK ONE CORPORATION & $4.80 \%$ & $4.92 \%$ & $\mathrm{X}$ & $\mathrm{X}$ & \\
\hline 07 & FLEETBOSTON FINANCIAL CORP. & $4.01 \%$ & $3.02 \%$ & $\mathrm{X}$ & $\mathrm{X}$ & \\
\hline 08 & U.S. BANCORP & $3.47 \%$ & $2.85 \%$ & $\mathrm{X}$ & $\mathrm{X}$ & \\
\hline 09 & HSBC NORTH AMERICA INC. & $2.51 \%$ & $1.90 \%$ & $\mathrm{X}$ & & \\
\hline 10 & SUNTRUST BANKS, INC. & $2.37 \%$ & $1.89 \%$ & $\mathrm{X}$ & & \\
\hline 11 & NATIONAL CITY CORPORATION & $1.86 \%$ & $1.72 \%$ & $\mathrm{X}$ & $\mathrm{X}$ & \\
\hline 12 & BB\&T CORPORATION & $1.73 \%$ & $1.36 \%$ & $\mathrm{X}$ & $\mathrm{X}$ & \\
\hline 13 & FIFTH THIRD BANCORP & $1.66 \%$ & $1.37 \%$ & $\mathrm{X}$ & $\mathrm{X}$ & \\
\hline 14 & BANK OF NEW YORK COMPANY & $1.64 \%$ & $1.39 \%$ & $\mathrm{X}$ & & $\mathrm{X}$ \\
\hline 15 & ABN AMRO NORTH AMERICA & $1.55 \%$ & $1.92 \%$ & $\mathrm{X}$ & & \\
\hline 16 & KEYCORP & $1.48 \%$ & $1.27 \%$ & $\mathrm{X}$ & $\mathrm{X}$ & \\
\hline 17 & STATE STREET CORPORATION & $1.38 \%$ & $1.32 \%$ & $\mathrm{X}$ & & $\mathrm{X}$ \\
\hline 18 & PNC FINANCIAL SERVICES GROUP & $1.32 \%$ & $1.03 \%$ & $\mathrm{X}$ & $\mathrm{X}$ & \\
\hline 19 & COMERICA INCORPORATED & $1.21 \%$ & $0.80 \%$ & $\mathrm{X}$ & $\mathrm{X}$ & \\
\hline 20 & UNIONBANCAL CORPORATION & $1.04 \%$ & $0.64 \%$ & $\mathrm{X}$ & & \\
\hline 21 & SOUTHTRUST CORPORATION & $1.02 \%$ & $0.79 \%$ & $\mathrm{X}$ & & \\
\hline 22 & M\&T BANK CORPORATION & $0.96 \%$ & $0.75 \%$ & $\mathrm{X}$ & & \\
\hline 23 & REGIONS FINANCIAL CORPORATION & $0.96 \%$ & $0.74 \%$ & $\mathrm{X}$ & & \\
\hline 24 & MBNA CORPORATION & $0.93 \%$ & $0.89 \%$ & $\mathrm{X}$ & & \\
\hline 25 & AMSOUTH BANCORPORATION & $0.89 \%$ & $0.69 \%$ & & & \\
\hline 26 & CHARTER ONE FINANCIAL, INC. & $0.80 \%$ & $0.64 \%$ & & & \\
\hline 27 & NORTHERN TRUST CORPORATION & $0.77 \%$ & $0.62 \%$ & & $\mathrm{X}$ & $\mathrm{X}$ \\
\hline 28 & UNION PLANTERS CORPORATION & $0.67 \%$ & $0.48 \%$ & & $\mathrm{X}$ & \\
\hline 29 & MARSHALL \& ILSLEY CORPORATION & $0.65 \%$ & $0.52 \%$ & & $\mathrm{X}$ & \\
\hline 30 & BANKMONT FINANCIAL CORP. & $0.64 \%$ & $0.58 \%$ & & & \\
\hline 31 & ZIONS BANCORPORATION & $0.61 \%$ & $0.43 \%$ & & & \\
\hline 32 & MELLON FINANCIAL CORPORATION & $0.61 \%$ & $0.51 \%$ & & $\mathrm{X}$ & $\mathrm{X}$ \\
\hline 33 & COMMERCE BANCORP, INC. & $0.61 \%$ & $0.34 \%$ & & & \\
\hline 34 & HUNTINGTON BANCSHARES & $0.54 \%$ & $0.46 \%$ & & & \\
\hline 35 & POPULAR, INC. & $0.53 \%$ & $0.55 \%$ & & & \\
\hline 36 & BANKNORTH GROUP, INC. & $0.52 \%$ & $0.40 \%$ & & & \\
\hline 37 & SYNOVUS FINANCIAL CORP. & $0.46 \%$ & $0.33 \%$ & & $\mathrm{X}$ & \\
\hline 38 & COMPASS BANCSHARES, INC. & $0.46 \%$ & $0.41 \%$ & & $\mathrm{X}$ & \\
\hline 39 & FIRST TENNESSEE NATIONAL CORP. & $0.46 \%$ & $0.37 \%$ & & $\mathrm{X}$ & \\
\hline 40 & NATIONAL COMMERCE FIN. CORP. & $0.45 \%$ & $0.35 \%$ & & & \\
\hline 41 & NORTH FORK BANCORPORATION, INC. & $0.44 \%$ & $0.32 \%$ & & & \\
\hline 42 & HIBERNIA CORPORATION & $0.41 \%$ & $0.28 \%$ & & & \\
\hline 43 & GREENPOINT FINANCIAL CORP. & $0.37 \%$ & $0.35 \%$ & & & \\
\hline 44 & CITY NATIONAL CORPORATION & $0.32 \%$ & $0.20 \%$ & & & \\
\hline 45 & FIRST CITIZENS BANCSHARES, INC. & $0.31 \%$ & $0.19 \%$ & & & \\
\hline 46 & PROVIDENT FINANCIAL GROUP, INC. & $0.30 \%$ & $0.26 \%$ & & & \\
\hline 47 & NEW YORK COMM. BANCORP, INC. & $0.30 \%$ & $0.35 \%$ & & & \\
\hline & Total & $97.16 \%$ & \begin{tabular}{|l|}
$93.86 \%$ \\
\end{tabular} & 24 & 20 & 4 \\
\hline
\end{tabular}


Note: The ranking in Table 1 is based on the top fifty U.S. bank holding companies (BHCs) by deposits as of year-end 2003 that have been publicly traded in the U.S. for five years. There are three exceptions to this filter that were included in the sample: HSBC North America, which began trading in July 1999; ABN Amro North America, which began trading in August 1999; and New York Community Bancorp, which began trading in November 2000. The three BHCs included in the list of top 50 by deposits that were excluded from our sample are Citizens Financial Group, whose parent BHC is not publicly traded; Bancwest Corporation, whose parent BHC in not publicly traded; and Taunus Corporation, whose parent BHC (Deutsche Bank) began trading in the U.S. only in October 2001. The deposit and asset percentages are of the totals for the sample of top 50 BHCs. The column labeled "top 25" lists the 24 BHCs in our second comparison peer group based on the publicly traded BHCs in the top 25 ranked by deposits as of year-end 2003. The column labelled "R.Bank-like" lists the BHCs in our "narrower" third comparison peer group as constructed using various economic criteria. The column labelled "Glob. Proc." lists the BHCs in our fourth comparison peer group as per the criteria in Rice and Stanton (2003). 
Table 2. Cost Recovery by the Federal Reserve Banks' Payments Services Business

Units: Millions of dollars

\begin{tabular}{|c|c|c|c|c|c|}
\hline Year & $\begin{array}{c}\text { Revenue from } \\
\text { Service }\end{array}$ & $\begin{array}{c}\text { Operating } \\
\text { Expenses and } \\
\text { imputed costs }\end{array}$ & $\begin{array}{c}\text { Targeted return } \\
\text { on equity }\end{array}$ & Total costs & $\begin{array}{c}\text { Cost recovery } \\
\text { (percent) }\end{array}$ \\
\hline 1990 & $\$ 746.5$ & $\$ 684.3$ & $\$ 33.6$ & $\$ 717.9$ & 104.0 \\
1991 & $\$ 750.2$ & $\$ 692.0$ & $\$ 32.5$ & $\$ 724.5$ & 103.5 \\
1992 & $\$ 760.8$ & $\$ 710.7$ & $\$ 24.9$ & $\$ 735.6$ & 103.4 \\
1993 & $\$ 774.5$ & $\$ 820.4$ & $\$ 17.5$ & $\$ 837.9$ & 92.4 \\
1994 & $\$ 767.2$ & $\$ 760.2$ & $\$ 21.0$ & $\$ 781.2$ & 98.2 \\
1995 & $\$ 765.2$ & $\$ 752.7$ & $\$ 31.5$ & $\$ 784.2$ & 97.6 \\
1996 & $\$ 815.9$ & $\$ 746.4$ & $\$ 42.9$ & $\$ 789.3$ & 103.4 \\
1997 & $\$ 818.8$ & $\$ 752.8$ & $\$ 54.3$ & $\$ 807.1$ & 101.5 \\
1998 & $\$ 839.8$ & $\$ 743.2$ & $\$ 66.8$ & $\$ 809.9$ & 103.7 \\
1999 & $\$ 867.6$ & $\$ 775.7$ & $\$ 57.2$ & $\$ 832.9$ & 104.2 \\
2000 & $\$ 922.8$ & $\$ 818.2$ & $\$ 98.4$ & $\$ 916.6$ & 100.7 \\
2001 & $\$ 960.4$ & $\$ 901.9$ & $\$ 109.2$ & $\$ 1,011.1$ & 95.0 \\
2002 & $\$ 918.3$ & $\$ 891.7$ & $\$ 92.5$ & $\$ 984.3$ & 93.3 \\
2003 & $\$ 881.7$ & $\$ 931.3$ & $\$ 104.7$ & $\$ 1,036.1$ & 85.1 \\
\hline
\end{tabular}

Source: Annual Reports of the Federal Reserve System 
Table 3. Payments revenue shares for the largest BHC peer group

\begin{tabular}{|c|cc|c|c|c|}
\hline \multirow{2}{*}{} & \multicolumn{3}{|c|}{ Ratio with respect to operating revenue: } & \multirow{2}{*}{} \\
\cline { 2 - 5 } & \multicolumn{4}{|c|}{ Sum } & \\
& \multicolumn{3}{|c|}{$\begin{array}{c}\text { Foregone } \\
\text { interest } \\
\text { Account } \\
\text { service } \\
\text { charges }\end{array}$} & $\begin{array}{c}\text { Credit } \\
\text { card } \\
\text { revenue } \\
\text { (FIR) }\end{array}$ \\
\hline $\mathbf{1 9 9 9}$ & $3.6 \%$ & $2.0 \%$ & $51.6 \%$ & $56.9 \%$ & $90.6 \%$ \\
$\mathbf{2 0 0 0}$ & $5.9 \%$ & $1.8 \%$ & $36.9 \%$ & $44.5 \%$ & $83.0 \%$ \\
$\mathbf{2 0 0 1}$ & $7.1 \%$ & $2.1 \%$ & $21.5 \%$ & $30.5 \%$ & $70.4 \%$ \\
$\mathbf{2 0 0 2}$ & $5.2 \%$ & $4.6 \%$ & $33.4 \%$ & $42.9 \%$ & $77.9 \%$ \\
$\mathbf{2 0 0 3}$ & $7.4 \%$ & $1.9 \%$ & $17.6 \%$ & $26.6 \%$ & $66.0 \%$ \\
\hline Average & $4.8 \%$ & $3.1 \%$ & $39.1 \%$ & $46.7 \%$ & $82.0 \%$ \\
\hline
\end{tabular}

Table 4. Average model selection criteria for the largest BHC peer group

\begin{tabular}{|l|c|c|c|c|}
\hline \multicolumn{1}{|c|}{ Model } & Average & & Average & \\
AIC & Model Ranking & BIC & Model Ranking \\
\hline M1: benchmark CAPM & 422.10 & 1 & 417.92 & 1 \\
M2: $\boldsymbol{\beta}_{\mathrm{EPi}}=\boldsymbol{\beta}_{\mathrm{RPi}}=\mathbf{0}$ & 425.77 & 2 & 419.50 & 6 \\
M3: $\boldsymbol{\beta}_{\mathrm{Ri}}=\boldsymbol{\beta}_{\mathrm{RPi}}=\mathbf{0}$ & 427.46 & 3 & 419.09 & 2 \\
M4: $\boldsymbol{\beta}_{\mathrm{Ri}}=\mathbf{0}$ & 427.46 & 4 & 419.09 & 3 \\
M5: $\boldsymbol{\beta}_{\mathrm{EPi}}=\mathbf{0}$ & 427.63 & 5 & 419.26 & 4 \\
M6: $\boldsymbol{\beta}_{\mathrm{RPi}}=\mathbf{0}$ & 427.84 & 6 & 419.47 & 5 \\
M7: Full four-factor model & 430.30 & 7 & 419.84 & 7 \\
\hline
\end{tabular}

The four-factor model estimated was:

$\mathrm{R}_{\mathrm{it}}-\mathrm{R}_{\mathrm{ft}}=\alpha_{\mathrm{i}}+\left(\beta_{\mathrm{Ei}}+\beta_{\mathrm{EPi}} \mathrm{PRS}_{\mathrm{it}}\right)\left(\mathrm{R}_{\mathrm{mt}}-\mathrm{R}_{\mathrm{ft}}\right)+\left(\beta_{\mathrm{Ri}}+\beta_{\mathrm{RPi}} \mathrm{PRS}_{\mathrm{it}}\right)\left(\mathrm{R}_{\mathrm{Lt}}-\mathrm{R}_{\mathrm{St}}\right)+\varepsilon_{\mathrm{it}}$,

The benchmark CAPM model has just $\alpha_{\mathrm{i}}$ and $\beta_{\mathrm{Ei}}$ as parameters. 


\section{Table 5. Hypothesis testing selection criteria for the largest BHC peer group}

The first column defines the null hypothesis. The second column lists the proportion of times out of 47 trials that the null hypothesis is accepted or rejected. Column 3 lists the p-value of the combined Pearson's $p_{\lambda}$ test for the six different null hypothesis. The last column lists the action or conclusion to follow depending on whether the null hypothesis is accepted or rejected. For example, if the first null hypothesis (H1) were accepted, then we would conclude that the benchmark model, Model 1, should be selected.

\begin{tabular}{|c|c|c|c|}
\hline Null hypothesis & $\begin{array}{l}\text { LR test accept | } \\
\text { reject percentages }\end{array}$ & $\begin{array}{l}\text { Pearson } \mathbf{p}_{\lambda} \\
\text { p-value }\end{array}$ & Action/Conclusion \\
\hline H1: benchmark CAPM & $91.5 \% \mid 8.5 \%$ & 0.997 & $\begin{array}{l}\text { No further tests/ single factor } \\
\text { CAPM appropriate }\end{array}$ \\
\hline H2: $\boldsymbol{\beta}_{\mathrm{EPi}}=\boldsymbol{\beta}_{\mathrm{RPi}}=0$ & $87.2 \% \mid 12.8 \%$ & 0.999 & $\begin{array}{l}\text { Test } \mathrm{H4} / \text { payments interaction } \\
\text { terms inappropriate }\end{array}$ \\
\hline H3: $\boldsymbol{\beta}_{\mathrm{Ri}}=\boldsymbol{\beta}_{\mathrm{RPi}}=\mathbf{0}$ & $\begin{array}{l}95.7 \% \mid 4.3 \% \\
\end{array}$ & 0.646 & $\begin{array}{l}\text { Test } \mathrm{H5} / \text { neither of the interest } \\
\text { rate terms is appropriate }\end{array}$ \\
\hline H4: $\boldsymbol{\beta}_{\mathrm{Ri}}=\mathbf{0}$ & \begin{tabular}{l|l|l}
$93.6 \%$ & $6.4 \%$
\end{tabular} & 0.957 & $\begin{array}{l}\text { No further tests/ interest rate } \\
\text { factor inappropriate }\end{array}$ \\
\hline H5: $\beta_{E P i}=0$ & $87.2 \% \mid 12.8 \%$ & 0.979 & $\begin{array}{l}\text { No further tests/ interaction } \\
\text { between payments revenue and } \\
\text { market factor inappropriate }\end{array}$ \\
\hline H6: $\boldsymbol{\beta}_{\mathrm{RPi}}=\mathbf{0}$ & $87.2 \% \mid 12.8 \%$ & 0.998 & $\begin{array}{l}\text { No further tests/ interaction } \\
\text { between payments revenue and } \\
\text { interest rate factor } \\
\text { inappropriate }\end{array}$ \\
\hline
\end{tabular}


Table 6. Distributional analysis of fitted values from the alternative specifications relative to the benchmark model

\begin{tabular}{|c|c|c|}
\hline Model & $\begin{array}{c}\text { Comparison of medians: } \\
\text { p-value for the two-sided } \\
\text { sign test }\end{array}$ & $\begin{array}{c}\text { Comparison of } \\
\text { distributions: } \\
\text { p-value for the Wilcoxon } \\
\text { two-sided rank test }\end{array}$ \\
\hline M2 & 0.64 & 0.86 \\
M3 & 0.19 & 0.08 \\
M4 & $0.00^{*}$ & 0.02 \\
M5 & 0.67 & 0.43 \\
M6 & 0.09 & 0.18 \\
M7 & $0.00^{*}$ & 0.06 \\
\hline
\end{tabular}

Note: *indicates we reject the null at the 5 percent level of significance.

Table 7. Average model selection criteria for the largest BHC peer group using panel regression techniques

\begin{tabular}{|l|c|c|c|c|}
\hline Model & $\begin{array}{c}\text { Average } \\
\text { AIC }\end{array}$ & $\begin{array}{c}\text { Model } \\
\text { Rank }\end{array}$ & $\begin{array}{c}\text { Average } \\
\text { BIC }\end{array}$ & Model Rank \\
\hline M1: benchmark CAPM & 19763.7 & 6 & 19787.4 & 6 \\
M2: $\boldsymbol{\beta}_{\mathbf{E P i}}=\boldsymbol{\beta}_{\mathbf{R P i}}=\mathbf{0}$ & 19764.1 & 7 & 19793.8 & 7 \\
M3: $\boldsymbol{\beta}_{\mathbf{R i}}=\boldsymbol{\beta}_{\mathbf{R P i}}=\mathbf{0}$ & 19681.9 & 3 & 19711.6 & 2 \\
M4: $\boldsymbol{\beta}_{\mathbf{R i}}=\mathbf{0}$ & 19673.3 & 2 & 19709.0 & 1 \\
M5: $\boldsymbol{\beta}_{\mathbf{E P i}}=\mathbf{0}$ & 19742.4 & 5 & 19778.1 & 5 \\
M6: $\boldsymbol{\beta}_{\mathbf{R P i}}=\mathbf{0}$ & 19682.5 & 4 & 19718.2 & 4 \\
M7: Full four-factor model & 19670.6 & 1 & 19712.2 & 3 \\
\hline
\end{tabular}


Table 8. Hypothesis testing selection criteria for the largest BHC peer group using panel regression techniques

\begin{tabular}{|l|c|}
\hline Null hypothesis & LR-test $\boldsymbol{p}$-value \\
\hline H1: benchmark CAPM & $0.00^{*}$ \\
H2: $\boldsymbol{\beta}_{\mathrm{EPi}}=\boldsymbol{\beta}_{\mathrm{RPi}}=\mathbf{0}$ & $0.00^{*}$ \\
H3: $\boldsymbol{\beta}_{\mathrm{Ri}}=\boldsymbol{\beta}_{\mathrm{RPi}}=\mathbf{0}$ & $0.00^{*}$ \\
H4: $\boldsymbol{\beta}_{\mathrm{Ri}}=\mathbf{0}$ & $0.03^{*}$ \\
H5: $\boldsymbol{\beta}_{\mathrm{EPi}}=\mathbf{0}$ & $0.00^{*}$ \\
H6: $\boldsymbol{\beta}_{\mathrm{RPi}}=\mathbf{0}$ & $0.00^{*}$ \\
\hline
\end{tabular}

Note: * indicates we reject the null at the 5 percent level of significance.

Table 9. Distributional analysis of fitted values from the alternative specifications relative to the benchmark model based on panel regression techniques

\begin{tabular}{|c|c|c|}
\hline Model & $\begin{array}{c}\text { Comparison of medians: } \\
\text { p-value for the two-sided } \\
\text { sign test }\end{array}$ & $\begin{array}{c}\text { Comparison of } \\
\text { distributions: } \\
\text { p-value for the Wilcoxon } \\
\text { two-sided rank test }\end{array}$ \\
\hline M2 & 0.06 & 0.60 \\
M3 & 0.09 & 0.23 \\
M4 & $0.00^{*}$ & $0.00^{*}$ \\
M5 & $0.03^{*}$ & 0.31 \\
M6 & $0.00^{*}$ & $0.04^{*}$ \\
\hline
\end{tabular}

Note: * indicates we reject the null at the 5 percent level of significance.

Table 10. Summary statistics on the COEs from the equity betas $(X=E$ adjustment type) from individual OLS regressions for each of the $47 \mathrm{BHCs}$ and the seven model specifications.

\begin{tabular}{|l|c|c|c|c|c|c|c|}
\hline & M1 & M2 & M3 & M4 & M5 & M6 & M7 \\
\hline Mean & 5.05 & 2.71 & 5.20 & -4.88 & -16.70 & 2.91 & -13.26 \\
\hline Sd & 3.09 & 6.69 & 3.07 & 11.16 & 14.01 & 6.57 & 14.01 \\
\hline se(mean) & 0.45 & 0.98 & 0.45 & 1.63 & 2.04 & 0.96 & 2.04 \\
\hline Max & 14.27 & 17.85 & 14.47 & 17.03 & 10.93 & 17.38 & 11.87 \\
\hline Min & 0.80 & -9.25 & 1.05 & -34.28 & -56.20 & -8.46 & -53.54 \\
\hline N & 47 & 47 & 47 & 47 & 47 & 47 & 47 \\
\hline p25 & 3.09 & -3.03 & 3.15 & -12.04 & -28.64 & -2.49 & -24.21 \\
\hline p50 & 3.71 & 2.78 & 3.92 & -4.23 & -14.79 & 2.83 & -10.80 \\
\hline p75 & 6.38 & 7.00 & 6.71 & 2.75 & -5.22 & 7.69 & -4.79 \\
\hline
\end{tabular}

